\title{
Mass spectrometry imaging of diclofenac and its metabolites in tissues using nanospray desorption electrospray ionization.
}

Hilary M. Brown, ${ }^{1}$ Daniela Mesa Sanchez, ${ }^{1}$ Ruichuan Yin, ${ }^{1}$ Bingming Chen, ${ }^{* 2}$ Marissa Vavrek, ${ }^{2}$ Mark T. Cancilla, ${ }^{2}$ Wendy Zhong, ${ }^{3}$ BaoJen Shyong, ${ }^{2}$ Rena Zhang, ${ }^{2}$ Fangbiao Li, ${ }^{2}$ and Julia Laskin*1

${ }^{1}$ Department of Chemistry, Purdue University, West Lafayette, Indiana 47907, United States

${ }^{2}$ Department of Pharmacokinetics, Pharmacodynamics, \& Drug Metabolism (PPDM), Merck \& Co., Inc., West Point, Pennsylvania 19486, United States

${ }^{3}$ Analytical Research \& Development, Merck \& Co., Inc., Rahway, New Jersey 07065, United States

KEYWORDS nanospray desorption electrospray ionization (nano-DESI), mass spectrometry imaging, diclofenac, metabolite localization, mouse kidney and liver tissue 


\begin{abstract}
Glucuronidation is a common phase II metabolic process for drugs and xenobiotics which increases their solubility for excretion. Acyl glucuronides (glucuronides of carboxylic acids) present concerns of toxicity as they have been implicated in gastrointestinal toxicity and hepatic failure. Despite the substantial success in the bulk analysis of these species, little is known about their localization in tissues. Herein, we used nanospray desorption electrospray ionization mass spectrometry imaging (nano-DESI-MSI) to examine the localization of diclofenac, a widely used nonsteroidal anti-inflammatory drug, and its metabolites in mouse kidney and liver tissues. NanoDESI allows for label-free imaging with high spatial resolution and sensitivity without special sample pretreatment. Using nano-DESI-MSI, ion images for diclofenac and its major metabolites were produced. MSI data acquired over a broad $\mathrm{m} / \mathrm{z}$ range showed fairly low signals of the drug and its metabolites. At least an order of magnitude improvement in the signals was obtained using selected ion monitoring (SIM), with $m / z$ windows centered around the low-abundance ions of interest. Using nano-DESI MSI in SIM mode, we observed that diclofenac acyl glucuronide is localized to the inner medulla and hydroxydiclofenac to the cortex of the kidney. The distributions observed for both metabolites closely match the previously reported localization of enzymes that process diclofenac into its respective metabolites. The localization of diclofenac acyl glucuronide to medulla likely indicates that the toxic metabolite is being excreted from the tissue. In contrast, a uniform distribution of diclofenac, hydroxydiclofenac and the diclofenac acyl glucuronide metabolite was observed in the liver tissue. Semiquantitative analysis found the metabolite to diclofenac ratios calculated from nano-DESI in agreement to those calculated from liquid chromatography tandem mass spectrometry (LC-MS/MS) experiments. Collectively, our results demonstrate nano-DESI-MSI can be successfully used to image diclofenac and its primary metabolites in dosed liver and kidney tissues from mice and derive semi-quantitative data from localized tissue regions.
\end{abstract}




\section{INTRODUCTION}

Diclofenac is a nonsteroidal anti-inflammatory drug typically used to treat pain and inflammation. ${ }^{1-8}$ The three major metabolites of diclofenac in both humans and mice are 4'hydroxydiclofenac, 5-hydroxydiclofenac, and diclofenac acyl glucuronide. ${ }^{1-5}$ Diclofenac is metabolized by a class of cytochrome P450 enzymes to produce both hydroxydiclofenac metabolites. The diclofenac acyl glucuronide is produced from the metabolism of diclofenac by a phase II uridine diphosphate glucuronosyl transferase (UGT) enzyme., ${ }^{3,9-11}$ These biotransformations are necessary in order to expedite drug elimination through bile and urine by increasing their water solubility. ${ }^{12,13}$ In humans, a large portion of diclofenac glucuronide is excreted renally as compared to being excreted through the bile in lab rats. ${ }^{14,15}$ The quinone-imine intermediates of the hydroxy metabolites as well as the diclofenac acyl glucuronide have been linked to hepatotoxicity and gastrointestinal toxicity in humans and rats. ${ }^{2,3,5,7-11,16}$ Diclofenac acyl glucuronide has a labile ester bond capable of spontaneously rearranging to form iso-glucuronides. A reactive keto group is exposed when the glucuronic acid ring opens, which can then covalently bind to proteins. Covalent interactions between acyl glucuronides and proteins is facilitated by high local concentrations of the metabolite, more alkaline $\mathrm{pH}$ of bile, or the protein is abundantly expressed. ${ }^{14}$ The reactivity of diclofenac's metabolites is hypothesized to initiate adverse drug reactions and toxicological effects. ${ }^{15}$

Concentrations of diclofenac and its metabolites in mouse, rabbit, and human plasma ${ }^{4,17,18}$ and mouse, human, urine ${ }^{1,7,19}$ have been determined by liquid chromatography tandem mass spectrometry (LC-MS/MS) previously. With LC analysis, the isomeric 4'- and 5-hydroxy metabolites have been separated., ${ }^{4,7}$ Furthermore, direct infusion followed by electron-induced dissociation (EID) has recently been used to identify both isomers based on the diagnostic fragments. ${ }^{5}$ Glucuronide metabolites have been analyzed using LC-MS/MS and quantified using the characteristic neutral loss of $176 \mathrm{~m} / \mathrm{z}$, corresponding to the loss of the sugar moiety ${ }^{12,20}$. Although LC-MS/MS enables the identification and quantification of diclofenac and its metabolites in tissues it cannot be used for examining their localization within the tissue sections.

Quantitative whole-body autoradiography (QWBA) is the standard method for determining the distribution of drugs in tissues. ${ }^{21-25}$ However, QWBA requires radio-labeling of the compound of interest and this technique does not provide molecular information. Therefore, the metabolites or possible degradation products cannot be distinguished from the precursor compound. If the radiolabel is lost during the metabolism process, these metabolites cannot be detected. ${ }^{21,22,25} \mathrm{~A}$ QWBA study was performed to determine the distribution of $\left[{ }^{14} \mathrm{C}\right]$ diclofenac in rats. The highest concentration of radio-labelled drug related material after 1 hour was found in the bile, followed by the esophagus, kidney, and liver which coincided with the typical metabolism route. ${ }^{6}$

To overcome the limitations of requiring a radiotracer for QWBA, label-free mass spectrometry imaging (MSI) has been implemented to determine drug and metabolite distributions in tissues. $^{21,25-27}$ MSI is a label-free technique that enables spatial localization of hundreds of molecules in tissues. ${ }^{28-31}$ Matrix assisted laser desorption ionization (MALDI) and desorption 
electrospray ionization (DESI) are by far the most commonly used ionization techniques in MSI experiments. ${ }^{25-27,30}$ Both MALDI and DESI have been used extensively for imaging of drugs in tissue sections. ${ }^{26,32-37}$ However, some drugs including diclofenac have presented a challenge to MALDI MSI. ${ }^{38}$ Phase II metabolites, including glucuronides, not observed using MALDI and DESI were successfully detected using liquid microjunction surface sampling indicating the potential of ambient ionization techniques based on liquid extraction for the analysis of these molecules in biological systems. ${ }^{25,39,40} \mathrm{In}$-source fragmentation of glucuronides resulting from the cleavage of the glucuronide moiety presents another challenge to their detection using MSI. ${ }^{20,41}$

We have developed nanospray desorption electrospray ionization ${ }^{42}$ (nano-DESI), a sensitive ambient ionization technique for MSI. ${ }^{43}$ Similar to DESI, this is a soft ionization technique that does not require sample pretreatment. In nano-DESI, the sample is probed using a liquid bridge formed between two capillaries and the extracted molecules are transferred to a mass spectrometer for analysis. ${ }^{43,44}$ The solvent supplied is typically $9: 1 \mathrm{MeOH} / \mathrm{H}_{2} \mathrm{O}$ but can be changed in order to increase extraction efficiency. ${ }^{45}$ Furthermore, quantitative imaging has been demonstrated by adding internal standards to the solvent. ${ }^{46,47}$ A spatial resolution of $\sim 10 \mu \mathrm{m}$ can be achieved using pulled capillaries. ${ }^{48-50}$ Nano-DESI has been used for quantitation of nicotine ${ }^{46}$ and small molecule

neurotransmitters. ${ }^{51}$ Quantification is accomplished by adding appropriate internal standards to the working solvent and does not require any additional sample preparation. Quantitation of lipids can also be achieved in a shotgun-like manner. ${ }^{47}$ Herein, we explore the capabilities of nano-DESI MSI for quantitative imaging of diclofenac and its metabolites in both kidney and liver tissues of dosed mice. Our results provide first insights into the localization of the drug and its metabolites in these tissues, which is of interest to understanding if accumulation or distribution of the drug or metabolites can be further linked to its toxicity.

\section{EXPERIMENTAL SECTION}

Chemicals. Diclofenac was purchased from Sigma (St. Louis, MO). Diclofenac-d4 (Cayman Chemical, Ann Arbor, MI) and arachidonic acid-d8 (Sigma) were used as internal standards for negative mode nano-DESI MSI experiments. Diclofenac acyl- $\beta$-D-glucuronide, 4'-hydroxy diclofenac, and 5-hydroxy diclofenac (Cayman Chemicals, Ann Arbor, MI) were used for ionization efficiency and suppression experiments. HPLC grade methanol and water for nanoDESI analysis and HPLC grade water and acetonitrile with $0.1 \%$ formic acid for LC analysis were purchased from Fisher Scientific (Hampton, NH).

Tissue Collection and Handling. Female C57BL/6 mice were orally dosed with $15 \mathrm{mg} / \mathrm{kg}$ of diclofenac. Diclofenac dosage solution was prepared by dissolving $2 \mathrm{mg} / \mathrm{mL}$ of diclofenac in water. Mice were sacrificed after 30 minutes by $\mathrm{CO}_{2}$ asphyxiation. All animal experiments were performed according to the institutional guidelines of Merck \& Co., Inc., Kenilworth, NJ, USA. Liver and kidney were snap frozen in hexane/dry ice bath and stored in a $-80^{\circ} \mathrm{C}$ freezer. Tissues were sectioned (thickness $=12 \mu \mathrm{m}$ ) using a Leica CM3050 S cryostat (Leica Biosystems, Buffalo 
Grove, IL). Sections were thaw-mounted onto glass slides for the imaging experiments, shipped on dry ice, and stored in a $-80{ }^{\circ} \mathrm{C}$ freezer until the analysis.

LC-MS/MS. Stock solutions of diclofenac, hydroxydiclofenac, and diclofenac acyl glucuronide were diluted with $50 / 50(\mathrm{v} / \mathrm{v}) \mathrm{ACN} / \mathrm{H}_{2} \mathrm{O}$ with $0.1 \%$ formic acid to create calibration standards ranging from $5 \mu \mathrm{M}$ to $1 \mathrm{nM}$ (Table S1). Diclofenac-d4 $(50 \mathrm{nM})$ was used as an internal standard for quantitation and added to each tissue section before extraction. Liver and kidney tissue sections (mass of sections in Table 1) of C57/B6 mice were extracted in a $2.0 \mathrm{~mL}$ Protein LoBind Tube (Eppendorf, Hamburg, Germany) using 50/50 (v/v) ACN/ $\mathrm{H}_{2} \mathrm{O}$ with $0.1 \%$ formic acid and $100 \mathrm{X}$ Halt protease \& phosphatase inhibitor (Thermo Scientific, Waltham, MA). The ratio of tissue to extraction solution was $1: 10 \mathrm{w} / \mathrm{v}$ (e.g. $1 \mathrm{mg}$ tissue to $10 \mu \mathrm{L}$ extraction solution). The tissue and extraction solution mixture were sonicated in a water bath at $37^{\circ} \mathrm{C}$ for 30 minutes followed by centrifugation $\left(10,000 \mathrm{RPM}\right.$ for 10 minutes at $\left.4^{\circ} \mathrm{C}\right)$. The supernatant was transferred to a clean vial to be analyzed via LC-MS/MS.

LC-MS/MS analyses were conducted using a Transcend LX2 UPLC (Thermo Fisher Scientific, Waltham, MA) system coupled to a QTRAP tandem mass spectrometer (Sciex, Framingham, MA). Ions were produced using electrospray ionization (ESI) on the QTRAP operated in positive mode. The chromatographic separation was achieved using an HSS T3 $(2.1 \times 50 \mathrm{~mm}, 2.5 \mu \mathrm{m})$ column (Waters, Milford, MA). The mobile phases consisted of $0.1 \%$ formic acid in water (mobile phase A) and $0.1 \%$ formic acid in methanol (mobile phase B). Gradient elution was as follows: 0$0.25 \mathrm{~min} 95 \% \mathrm{~A}, 5 \% \mathrm{~B} ; 0.25-1.75 \mathrm{~min}$ linear gradient to $5 \% \mathrm{~A}, 95 \% \mathrm{~B} ; 1.75-2.25 \mathrm{~min} 5 \% \mathrm{~A}$, $95 \% \mathrm{~B} ; 2.25-2.5 \mathrm{~min}$ equilibrate with $95 \% \mathrm{~A}, 5 \% \mathrm{~B}$ and then hold for $0.5 \mathrm{~min}$ at $95 \% \mathrm{~A}, 5 \% \mathrm{~B}$. In each experiment, $5 \mu \mathrm{L}$ of a sample was injected at a flow rate of $0.75 \mathrm{~mL} / \mathrm{min}$. The multiple reaction monitoring (MRM) transitions for diclofenac, hydroxy metabolite, diclofenac acyl glucuronide metabolite, and diclofenac-d4 (internal standard) are listed in Table S2.

Nano-DESI Imaging. A custom nano-DESI source ${ }^{44}$ with shear force feedback ${ }^{52}$ was interfaced to a Q-Exactive HF-X MS (Thermo Fisher Scientific, Waltham, MA). The nano-DESI probe is comprised of two $150 \mu \mathrm{m}$ OD x $50 \mu \mathrm{m}$ ID fused silica capillaries. The primary capillary delivers the extraction solvent $\left(9: 1 \mathrm{MeOH} / \mathrm{H}_{2} \mathrm{O}\right)$ to the sample and a secondary capillary transfers the extracted molecules to the MS inlet. A third capillary is used as the shear force probe that maintains a constant distance between the nano-DESI probe and the sample. ${ }^{48}$ The shear force capillary (800 $\mu \mathrm{m}$ OD x $200 \mu \mathrm{m}$ ID) is pulled to a $20 \mu \mathrm{m}$ OD tip using a P-2000 micropipette puller system (Sutter Instruments, Novato, CA). All capillaries are positioned using high-resolution micromanipulators (XYZ 500MIM, Quater Research and Development, Bend, OR) and monitored using two Dino-Lite digital microscopes (AnMo Electronics Corporation, Sanchong, New Taipei, Taiwan). The 9:1 (v/v) methanol/water extraction solvent containing internal standards is used for negative ionization mode. Negative mode internal standards used in this study include arachidonic acid-d8 and diclofenac-d4 $(0.5 \mu \mathrm{M})$. The solvent flow rate is $500 \mathrm{~nL} / \mathrm{min}$ with a voltage of $3.2 \mathrm{kV}$. The capillary inlet is heated to $250{ }^{\circ} \mathrm{C}$. The funnel RF level is optimized to minimize in-source fragmentation and set to 20 . Imaging experiments are performed by scanning each sample line by 
line under the shear force/nano-DESI probe at a constant velocity of $40 \mu \mathrm{m} / \mathrm{s}$ while collecting highresolution mass spectra $(\mathrm{m} / \Delta \mathrm{m}$ of 60,000 at $200 \mathrm{~m} / \mathrm{z})$ at a rate of $7 \mathrm{~Hz}$. The spacing between the lines was $150 \mu \mathrm{m}$ setting the upper limit of the spatial resolution to $150 \mu \mathrm{m}$. We note that because the pixel size in the $\mathrm{x}$-dimension is much smaller $(\sim 10 \mu \mathrm{m})$, the spatial resolution achieved in these experiments is better than $150 \mu \mathrm{m}$. Dimensions of scanned area for kidney sections was $\sim 10 \mathrm{x} 6$ $\mathrm{mm}^{2}$ with an acquisition time of $\sim 3.5$ hours per section. Dimensions of the liver sections were $\sim 10 \times 17 \mathrm{~mm}^{2}$ with an average acquisition time of $\sim 8 \mathrm{hrs}$ per section. For ionization efficiency and ion suppression experiments, individual line scans across the tissue were performed with varying concentrations of diclofenac acyl- $\beta$-D-glucuronide and 4'-hydroxy diclofenac $(0,5.0,10,15,20$ $\mu \mathrm{M})$ and a constant concentration of diclofenac-d4 $(5 \mu \mathrm{M})$.

Data Processing. Diclofenac and its metabolites observed in the MSI experiments were identified based on the accurate mass measurement and MS/MS. Raw data were collected using Xcalibur software (Thermo Scientific) and subsequently processed using Peak-by-Peak (SpectroSwiss, Lausanne, Switzerland). SIM imaging experiments were processed using an in-house script described in our previous publication, ${ }^{53}$ and manually normalized using Origin (OriginLab Corporation). Region of interest analysis was done by manually averaging pixel intensities matrices in Microsoft Excel.

\section{RESULTS AND DISCUSSION}

In this study, we examine the spatial localization of diclofenac and its major metabolites in kidney and liver tissue. The nano-DESI MSI setup is shown schematically in Figure 1A. The primary and secondary capillary are positioned close to each other to generate a stable liquid bridge. The primary capillary supplies solvent to the liquid bridge at a constant rate. Analytes extracted into the liquid bridge are transferred through the secondary capillary to a mass spectrometer inlet and ionized by ESI. The shear force probe maintains a constant distance between the sample and the nano-DESI probe. The inset image shows a photograph of the probe placed on kidney tissue. Figure 1B shows the average negative mode nano-DESI mass spectrum of the dosed kidney tissue in the $m / z$ 150-500 range. This $m / z$ range encompasses diclofenac, its major metabolites, and endogenous fatty acids from the tissue. Both the drug and its metabolites are observed as minor species in the spectrum. Figures 1C and 1D highlight two $\mathrm{m} / \mathrm{z}$ ranges $(\mathrm{m} / \mathrm{z} 290-315$ and $\mathrm{m} / \mathrm{z}$ 460480) containing [M-H] ion of diclofenac at $m / z 294.0098$ (D), [M-H] $]^{-}$ion of diclofenac-d4 at $m / z$ 298.0348 (D-d4), [M-H] $]^{-}$ion of hydroxydiclofenac at $\mathrm{m} / \mathrm{z} 310.0048(\mathrm{HD})$, and $[\mathrm{M}-\mathrm{H}]^{-}$ion of diclofenac acyl glucuronide metabolite at $m / z 470.0424$ (AG). 

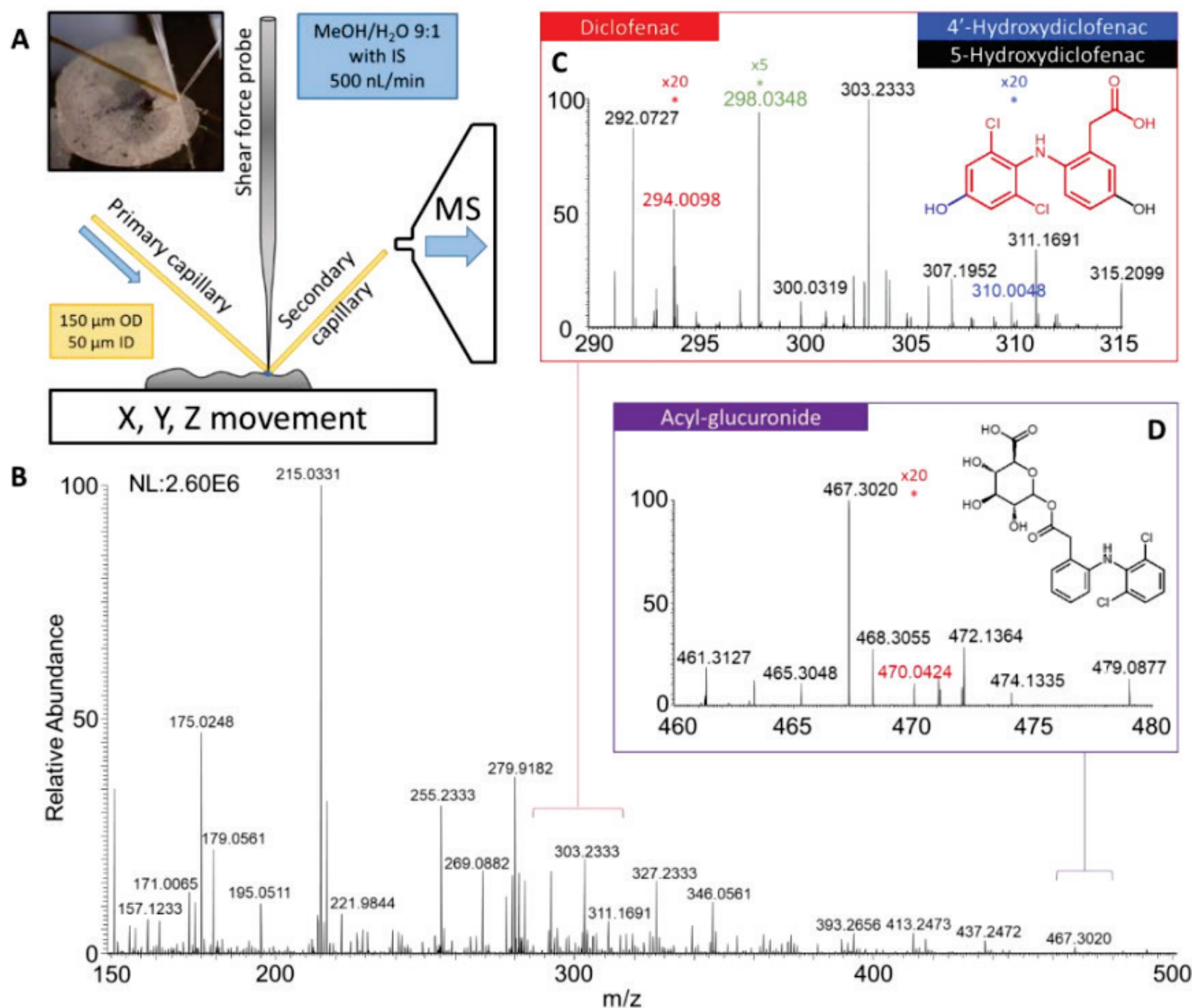

Figure 1. (A) Schematic drawing of the nano-DESI system positioned in front of a mass spectrometer inlet showing the nano-DESI probe comprised of two fused silica capillaries for solvent delivery and ESI, and a shear force capillary for maintaining constant distance between the sample and probe. (B) Negative ion mode mass spectrum of diclofenac dosed mouse kidney tissue in the $m / z$ 150-500 range. (C) Expanded view of the $m / z$ 290-315 range. Diclofenac (red, $m / z$ 294), diclofenac-d4 (green, $m / z$ 298), 4'- and 5-hydroxydiclofenac (blue, $m / z$ 310) are present. The inset structure corresponds to diclofenac (red) with additional modifications for 4'-hydroxydiclofenac (blue, 4' carbon -OH group) and 5-hydroxydiclofenac (black, 5 carbon -OH group). (D) Expanded view of the $m / z$ 460-480 range. The structure of the acyl glucuronide metabolite (red, $\mathrm{m} / \mathrm{z} 470$ ) is shown in inset.

Although nano-DESI is a soft ionization technique, in our initial experiments, we observed a substantial fragmentation of D-d4. Similar fragmentation was observed in direct infusion experiments and attributed to in-source fragmentation of the analyte. Upon further investigation of the instrument conditions we found that in-source fragmentation could be minimized by adjusting the funnel RF level of the Q-Exactive HF-X system. Using the default funnel RF setting of 100, we observed predominately the decarboxylated fragment of D-d4 $(\mathrm{m} / \mathrm{z} 254.0440)$ (Figure S1A). When the funnel RF was adjusted to 0, very little fragmentation occurs and the intact [M$\mathrm{H}]^{-}$peak ( $m / z$ 298.0337) for D-d4 is observed with high intensity (Figure S1B). However, ion 
transmission at $\mathrm{RF}=0$ is fairly low. The funnel $\mathrm{RF}$ level was further optimized by monitoring the signal-to-noise ratio of D-d4 and its fragment while varying the funnel RF from 0 to 100 (Figure S1C). We found that the funnel RF level of 20 provided the best signal of D-d4 without any measurable in-source fragmentation.

Diclofenac dosed kidney tissue was imaged using nano-DESI MSI in both broadband mode (Full MS) and selected ion monitoring (SIM) mode. The resulting ion images normalized to D-d4 as well as H\&E and optical images are shown in Figure 2. The H\&E stained image was annotated to highlight important anatomical regions. For kidney sections imaged using broadband mode, D has an even distribution throughout the tissue and HD is localized to the cortex. Meanwhile, AG is tightly localized to the inner medulla of the kidney, but some signal can be seen in the cortex. In SIM imaging mode, the localization patterns of diclofenac and its metabolites are comparable to the images obtained in the broadband mode, but the intensities are enhanced, and noise is substantially reduced resulting in an order of magnitude increase in signal-to-noise ratio. By increasing the ion abundance, SIM imaging provides higher-quality localization patterns of the drug and metabolites in the sample. The spatial distribution of AG obtained using SIM mode is in better agreement with the known distribution of UGTs in the kidney tissue. These localization patterns are consistent across left and right kidney and across replicate tissue sections as seen in Figure S2.

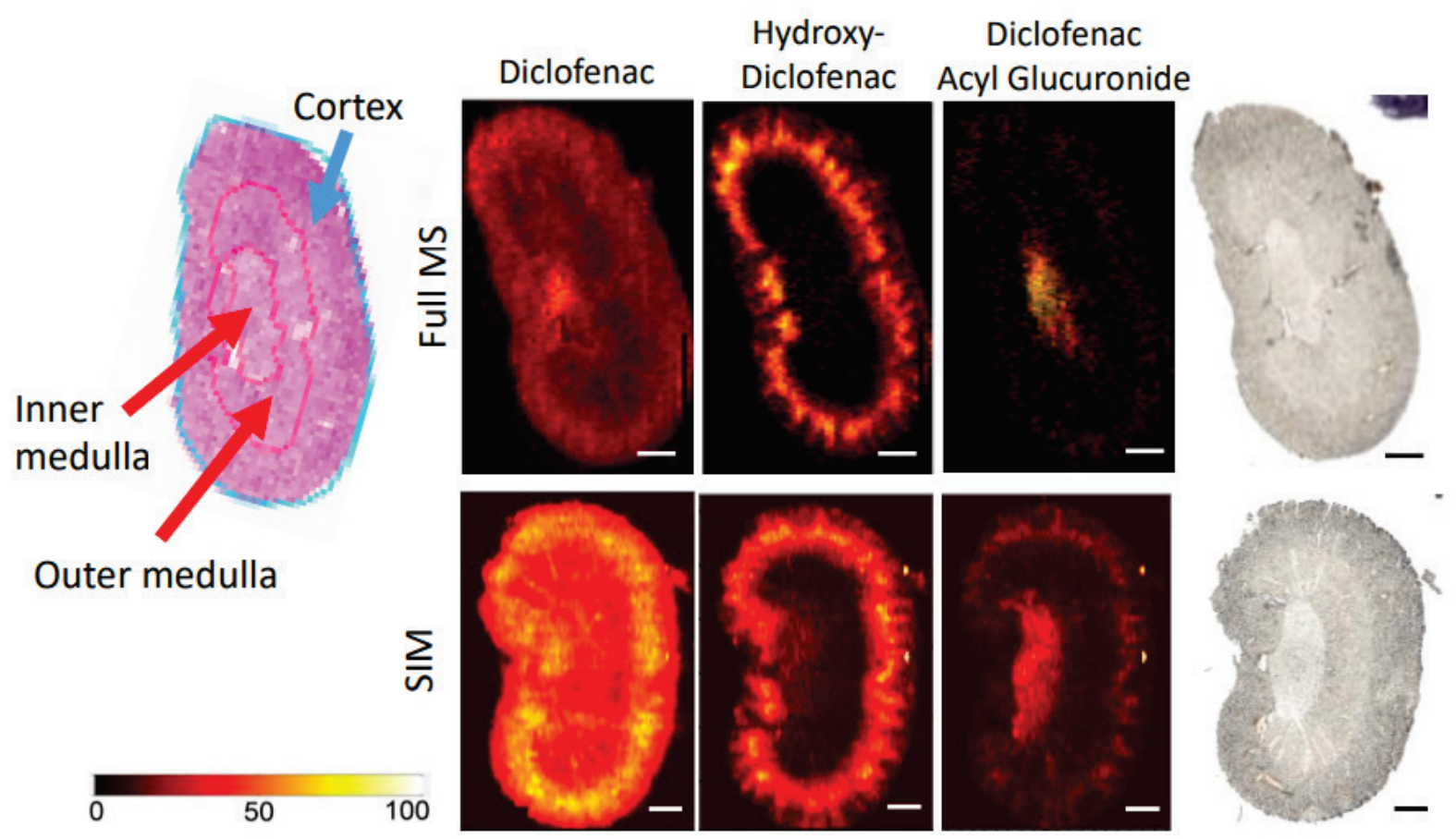

Figure 2. H\&E, optical, and nano-DESI ion images of diclofenac dosed mouse kidney tissue. Relevant regions of $\mathrm{H} \& \mathrm{E}$ stained kidney section are annotated for comparison with ion images. Ion images of diclofenac, acyl glucuronide, and hydroxydiclofenac are shown for both broadband (Full MS) and SIM imaging modes on kidney. Ion images are self-normalized to the internal standard, diclofenac-d4. Scale bar represents $1 \mathrm{~mm}$. Intensity scale ranges from $0 \%$ intensity (black) to $100 \%$ (white). 
The liver is the primary organ for drug metabolism ${ }^{54,55}$, therefore, dosed mouse liver tissue was also imaged to investigate metabolite distribution. The resulting ion images normalized to D-d4 and the corresponding optical and H\&E images are shown in Figure 3. D is uniformly distributed across the liver tissue section (Figure 3A), which is consistent with the localization of both cytochrome P-450 and UGT enzymes, known to catalyze metabolic reactions in liver cells and the liver being a high blood perfused organ. ${ }^{56,57}$ However, ion images of both HD and AG metabolites show very low signal in the broadband imaging mode. These images are consistent across multiple tissue section replicates (Figure S3). Based on previous literature, both HD and AG metabolites are expected to be present in liver. ${ }^{54-57}$ Since very little signal intensity was seen in the ion images, LC-MS/MS quantitation was performed to determine if the concentration of these metabolites was below the MSI limit of detection. Table 1 shows the concentration of diclofenac and its metabolites in both kidney and liver tissue determined by LC-MS/MS quantitation. The concentration of the AG in liver (avg. $2.5 \mu \mathrm{M}$ ) and kidney (avg. $3.3 \mu \mathrm{M}$ ) are similar after 30 minutes post dose. In kidney, the average concentration of HD was $21.6 \mu \mathrm{M}$ and $0.95 \mu \mathrm{M}$ in the liver. Overall, the concentration of metabolites was higher in the kidney tissue but still present within the same order of magnitude concentration in the liver. These results indicate that the lack of metabolite signal in nano-DESI MSI of liver sections is likely related to the stronger signal suppression in this sample. Abundant bile acids present in the full MS spectrum of dosed liver tissue (Figure 3B) likely contribute to the observed signal suppression of acyl glucuronide. In order to increase for the sensitivity of MSI experiments towards diclofenac and its metabolites, we analyzed liver sections using SIM imaging mode. The resulting ion images of liver sections shown in Figure 3C, reveal both $\mathrm{HD}$ and $\mathrm{AG}$ in this sample. Both, $\mathrm{HD}$ and $\mathrm{AG}$ are distributed evenly throughout the liver tissue, with slight enhancements in hepatic veins. Overall, the SIM imaging mode helped improve signal-to-noise ratios of diclofenac and its metabolites in both liver and kidney tissue by at least an order of magnitude and was able to provide better ion images of both diclofenac metabolites. 
A
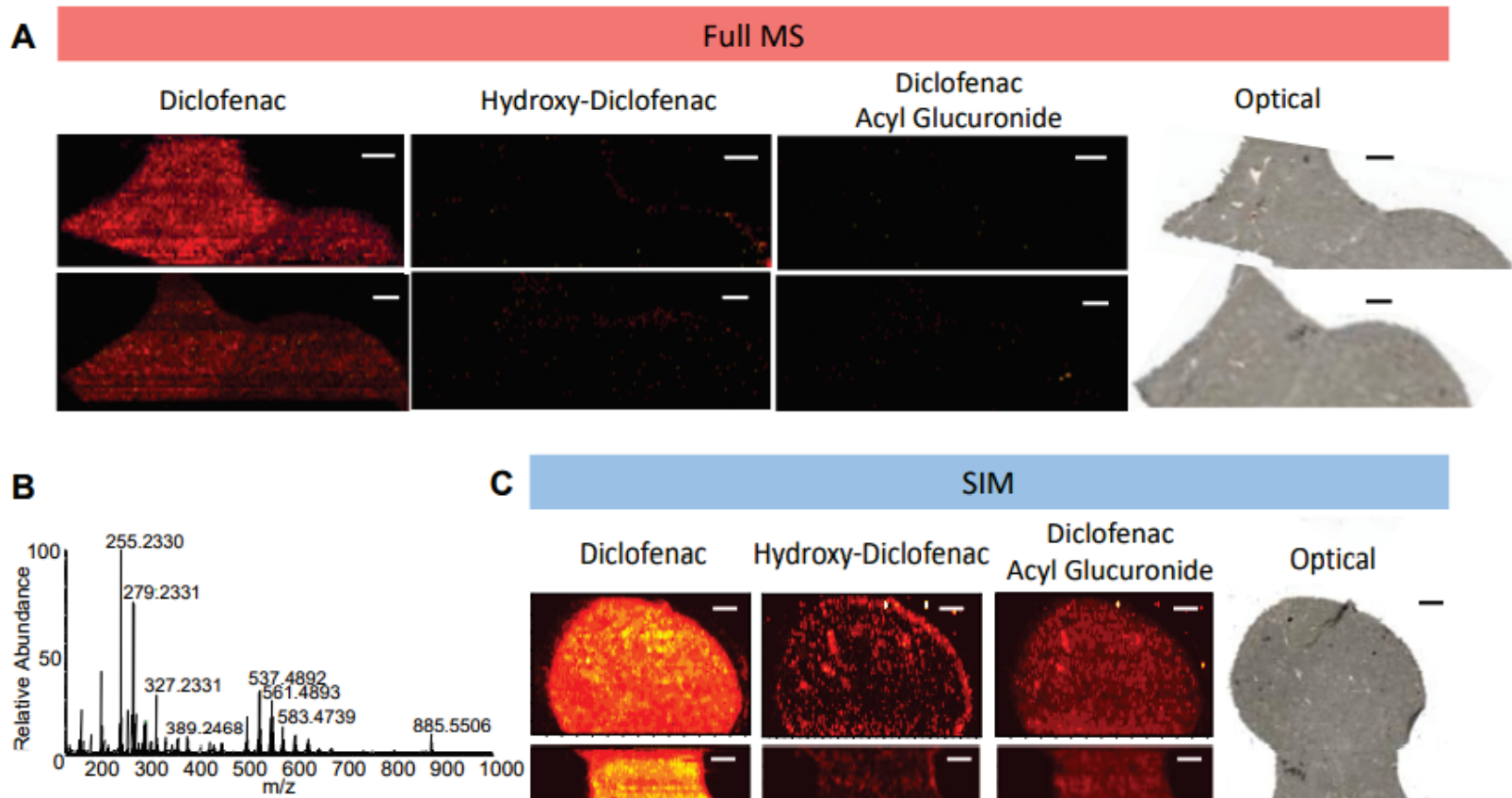

C

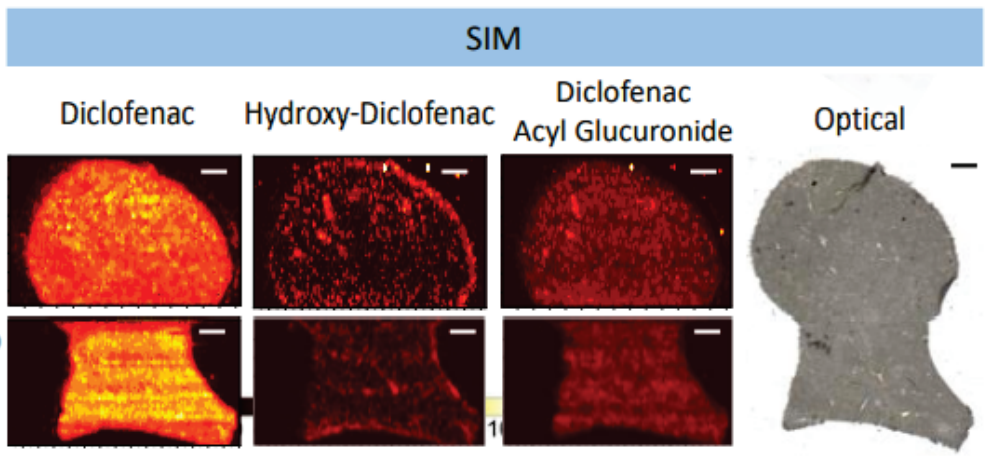

Figure 3. (A) Optical and nano-DESI ion images of diclofenac, acyl glucuronide, and hydroxydiclofenac are shown for two different dosed mouse liver sections for broadband (Full MS) imaging mode. (B) Broadband mode mass spectrum, mass range $\mathrm{m} / \mathrm{z}$ 133-1000. (C) Optical and nano-DESI ion images of diclofenac, acyl glucuronide, and hydroxydiclofenac for SIM imaging mode. Ion images are self-normalized to internal standard, diclofenac-d4. Scale bar represents $1 \mathrm{~mm}$. Intensity scale ranges from $0 \%$ intensity (black) to $100 \%$ (white).

Table 1. Concentrations of diclofenac and its major metabolites in kidney and liver tissue from LC-MS/MS quantitative method. Dosed tissue samples and control tissues were run in triplicate. Hydroxydiclofenac was not stable in kidney tissue homogenate and could not be accurately quantified but significant amount was observed. Therefore (*) denotes a semi-quantitative measurement. The value denoted in parenthesis besides the metabolite concentrations are the metabolite/diclofenac ratio.

\begin{tabular}{lcccc} 
Tissue type & $\begin{array}{c}\text { Tissue } \\
\text { Weight }(\mathbf{m g})\end{array}$ & $\begin{array}{c}\text { Diclofenac } \\
(\boldsymbol{\mu} \mathbf{M})\end{array}$ & $\begin{array}{c}\text { Hydroxydiclofenac } \\
(\boldsymbol{\mu M})\end{array}$ & $\begin{array}{c}\text { Diclofeanc-acyl- } \boldsymbol{\beta}- \\
\text { D-glucuronide }(\boldsymbol{\mu M})\end{array}$ \\
\hline Kidney & 2.36 & 12.25 & $18^{*}(1.5)$ & $2.71(0.221)$ \\
\hline Kidney & 2.43 & 14.38 & $19^{*}(1.3)$ & $3.43(0.239)$ \\
\hline Kidney & 2.55 & 16.14 & $28^{*}(1.7)$ & $3.67(0.227)$ \\
\hline & & & & \\
\hline Liver & 2.64 & 22.54 & $1.35(0.0599)$ & $2.41(0.107)$ \\
\hline Liver & 2.75 & 18.08 & $0.55(0.030)$ & $2.42(0.134)$ \\
\hline Liver & 2.91 & 24.38 & $0.95(0.039)$ & $2.67(0.110)$ \\
\hline
\end{tabular}


Given the increase in signal in SIM imaging mode, we were able to obtain metabolite signals above the limit of quantitation for comparison with LC-MS/MS quantification data (Table 1). For relative quantification, we explored the varying ionization efficiencies of the analytes and their suppression on the tissue. Specifically, we performed a series of experiments, in which we acquired nano-DESI line scans using 9:1 $\mathrm{MeOH} / \mathrm{H}_{2} \mathrm{O}$ solvent containing a mixture of $\mathrm{HD}$ and $\mathrm{AG}$ at $0,5.0$, $10,15,20 \mu \mathrm{M}$ each and a constant concentration of D-d4 of $5 \mu \mathrm{M}$. Signals of standards observed in these experiments are used to quantify signal suppression over a range of concentrations. The results shown in Figure S4 indicate that signals of standards increase proportionally with concentration. We obtained suppression factors ( $\mathrm{SF}$ metabolite) from the slopes of the respective linear plots. Full data and calculations for both broadband and SIM experiments can be found in the Supporting Information. The suppression factors obtained for liver and kidney for SIM experiments are presented in Table 2. The results show a substantial suppression of AG compared to HD in the analysis of both tissues. The suppression factors are 12 and 10 for AG and 2.0 and 2.7 for HD in kidney and liver, respectively. These suppression factors take into account both differences in ionization efficiencies and tissue extinction coefficients of diclofenac and its metabolites.

Table 2. Ratios of hydroxydiclofenac (HD) and diclofenac acyl glucuronide (AG) to diclofenac (D) for both LCMS/MS and nano-DESI methods. Nano-DESI values correspond to SIM experiment and have been corrected to account for tissue suppression (multiplied by the corresponding suppression factor $(\dagger)$ also shown). (*) Denotes semiquantitative value due to standard instability in tissue homogenate. Suppression values are derived from the slope of a range of normalized metabolite on-tissue signal intensities in a nano-DESI SIM experiment.

\begin{tabular}{llr|r}
\hline Kidney & & & \\
\hline \hline & & HD/D & AG/D \\
\hline LC-MS/MS & whole tissue & $1.5^{*}$ & 0.23 \\
\hline Nano-DESI & whole tissue & 0.8 & 2.1 \\
\hline Nano-DESI & cortex & 1.0 & 1.6 \\
\hline Nano-DESI & outer medulla & 0.34 & 1.6 \\
\hline Nano-DESI & inner medulla & 0.40 & 5.3 \\
\hline$\dagger$ Nano-DESI Suppression Factors & 2.0 & 12 \\
\hline
\end{tabular}

\section{Liver}

\begin{tabular}{lrr|r}
\hline \hline & & HD/D & AG/D \\
\hline LC-MS/MS & whole tissue & 0.043 & 0.12 \\
\hline Nano-DESI & whole tissue & 0.022 & 1.4 \\
\hline$\dagger$ Nano-DESI Suppression Factors & 2.7 & 10.0 \\
\hline
\end{tabular}


Using these suppression factors, we calculated concentration ratios from the intensity ratios obtained in SIM imaging experiments adjusted for signal suppression (i.e. measured (Imetabolite/Idiclofenac * SFmetabolite). Specifically, we performed region of interest (ROI) analysis to determine signal intensities of $\mathrm{D}, \mathrm{HD}$, and $\mathrm{AG}$ across the whole tissue $(\mathrm{HD} / \mathrm{D}=0.8 ; \mathrm{AG} / \mathrm{D}=2.1)$ and in specific regions including cortex $(\mathrm{HD} / \mathrm{D}=1.0 ; \mathrm{AG} / \mathrm{D}=1.6)$, outer medulla $(\mathrm{HD} / \mathrm{D}=0.34$; $\mathrm{AG} / \mathrm{D}=1.6)$ and inner medulla $(\mathrm{HD} / \mathrm{D}=0.40 ; \mathrm{AG} / \mathrm{D}=5.3)$ of the kidney section. Meanwhile, because all analytes are distributed evenly in the liver tissue, we only considered the average signals across the entire liver tissue $(\mathrm{HD} / \mathrm{D}=0.022 ; \mathrm{AG} / \mathrm{D}=1.4)$ for comparison with $\mathrm{LC}-\mathrm{MS} / \mathrm{MS}$. Table 2 shows the resulting concentration ratios obtained from nano-DESI MSI in comparison with the averaged ratios obtained from the LC-MS/MS quantification. Although only a semiquantitative LC-MS/MS determination of HD in kidney homogenate was obtained due to the instability of HD in kidney tissue homogenate, comparable results were obtained for HD/D ratios of the whole tissue. However, the AG/D ratios obtained using nano-DESI MSI are about an order of magnitude higher than the concentration ratios obtained using LC-MS/MS. This could likely be due to hydrolysis of AG during LC-MS/MS analysis or degradation during homogenization and extraction. The $\mathrm{pH}$-dependent degradation and difficulties of characterizing acyl glucuronides

have been previously explored in the literature. ${ }^{58}$ Regardless, both experiments generally agree that $\mathrm{HD}$ is present in higher abundance in kidney than AG. Meanwhile AG is in higher abundance than HD in liver for both the LC-MS/MS and nano-DESI analyses.

Region-specific concentration ratios obtained from nano-DESI MSI experiments performed in SIM mode summarized in Table 2, allow for the relative comparison of metabolite concentrations among different kidney regions. For kidney tissue, the highest HD/D ratio of 1.0 is observed in the cortex indicating that $\mathrm{HD}$ is most abundant in this region of the tissue and less abundant in both in the outer medulla $(\mathrm{HD} / \mathrm{D}=0.34)$ and inner medulla $(\mathrm{HD} / \mathrm{D}=0.40)$. Meanwhile, $\mathrm{AG}$ is tightly localized to the inner medulla $(\mathrm{AG} / \mathrm{D}=5.3)$ and similarly less abundant in the cortex $(\mathrm{AG} / \mathrm{D}=1.6)$ and outer medulla $(\mathrm{AG} / \mathrm{D}=1.6)$. These values corroborate the qualitative assessment of the nanoDESI images. Overall, the relative quantification using nano-DESI MSI is comparable to LCMS/MS data and has the distinct advantage of providing localized quantification for comparison of the different regions of the tissue.

\section{CONCLUSIONS}

In this study, we evaluated the performance of nano-DESI MSI for imaging of drugs and metabolites, which are difficult to detect due to a substantial signal suppression in MSI experiments. In particular, we used nano-DESI MSI to image diclofenac dosed liver and kidney tissues from mice. In the full MS mode, we observed diclofenac and its major metabolites in the kidney tissue but could not detect diclofenac metabolites in the liver. A substantial improvement in the abundances of these species was observed in the SIM mode. Imaging experiments, in which 
several SIM $\mathrm{m} / \mathrm{z}$ filters around the metabolites of interest were applied in sequence to help reduce ion suppression from other ions, revealed the localization of diclofenac and its metabolites and enabled relative quantification. In the kidney, diclofenac is evenly distributed throughout the tissue. HD is localized to the cortex of the kidney where the majority of cytochrome P450 enzymes are that metabolize diclofenac into HD. Meanwhile, AG is localized to the inner medulla of the kidney, which is the area of the kidney where xenobiotics are excreted after metabolism. AG is more polar than HD and is likely localized in the inner medulla for rapid excretion. These distributions are reproducible across the left and right kidney and across multiple tissue sections. In liver tissue, diclofenac is evenly distributed throughout the tissue. Meanwhile, HD and AG observed throughout the tissue are slightly enhanced in hepatic veins. Relative quantification of $\mathrm{HD}$ and $\mathrm{AG}$ across the tissue and in specific regions provides first insights into the chemical gradients of these metabolites in the tissue. Comparison with LC-MS/MS quantitation indicated that nano-DESI MSI is well-suited for determining region-specific relative abundances of drugs and metabolites in dosed tissues. Future work may expand this study from a single time point to a time series to gain a better understanding of drug metabolism and pharmacokinetics.

\section{ACKNOWLEDGMENTS}

This work was supported by Merck Sharp \& Dohme Corp. a subsidiary of Merck \& Co., Inc., Kenilworth, NJ, USA, under a Master Agreement with Purdue University on Chemical Instrumentation. The authors thank Dr. Elizabeth Pierson (Merck \& Co., Inc., Kenilworth, NJ, USA) for helpful discussions. The experimental platform used in this research was developed under the support from the National Science Foundation (NSF-1808136, JL). DMS acknowledges

support from the National Science Foundation Graduate Research Fellowship Program under Grant No. (DGE-1333468). Any opinions, findings, and conclusions or recommendations expressed in this material are those of the author(s) and do not necessarily reflect the views of the National Science Foundation.

\section{ASSOCIATED CONTENT}

Supporting Information. The Supporting Information is available free of charge on the ACS Publications website.

\section{AUTHOR INFORMATION}

Corresponding Authors

*Tel: 765-494-5464. E-mail: jlaskin@purdue.edu

*Tel: 215-652-9213. Email: bingming.chen@merck.com 


\section{Notes}

The authors declare no competing financial interest.

\section{REFERENCES}

(1) Stierlin, H.; Faigle, J. W.; Sallmann, A.; Kung, W.; Richter, W. J.; Kriemler, H.-P.; Alt, K. O.; Winkler, T. Biotransformation of Diclofenac Sodium (Voltaren ${ }^{\circledR}$ ) in Animals and in Man. Xenobiotica 1979, 9 (10), 601-610. https://doi.org/10.3109/00498257909042327.

(2) Kenny, J. R.; Maggs, J. L.; Meng, X.; Sinnott, D.; Clarke, S. E.; Park, B. K.; Stachulski, A. V. Syntheses and Characterization of the Acyl Glucuronide and Hydroxy Metabolites of Diclofenac. J. Med. Chem. 2004, 47 (11), 2816-2825. https://doi.org/10.1021/jm030891w.

(3) Daly, A. K.; Aithal, G. P.; Leathart, J. B. S.; Swainsbury, R. A.; Dang, T. S.; Day, C. P. Genetic Susceptibility to Diclofenac-Induced Hepatotoxicity: Contribution of UGT2B7, CYP2C8, and ABCC2 Genotypes. Gastroenterology 2007, 132 (1), 272-281. https://doi.org/10.1053/j.gastro.2006.11.023.

(4) Sparidans, R. W.; Lagas, J. S.; Schinkel, A. H.; Schellens, J. H. M.; Beijnen, J. H. Liquid Chromatography-Tandem Mass Spectrometric Assay for Diclofenac and Three Primary Metabolites in Mouse Plasma. J. Chromatogr. B 2008, 872 (1-2), 77-82. https://doi.org/10.1016/j.jchromb.2008.07.012.

(5) Liang, Z.; Zhang, Z.; Wolff, J. J.; Thompson, C. J.; Zhong, W. Implementation of ElectronInduced Dissociation Mass Spectrometry Technique for Differentiation of Isomeric Metabolites of Diclofenac. Rapid Commun. Mass Spectrom. 2017, 31 (17), 1471-1475. https://doi.org/10.1002/rcm.7924.

(6) Schweitzer, A.; Hasler-Nguyen, N.; Zijlstra, J. Preferential Uptake of the Non Steroid AntiInflammatory Drug Diclofenac into Inflamed Tissues after a Single Oral Dose in Rats. BMC Pharmacol. 2009, 9 (1), 5. https://doi.org/10.1186/1471-2210-9-5.

(7) Sarda, S.; Page, C.; Pickup, K.; Schulz-Utermoehl, T.; Wilson, I. Diclofenac Metabolism in the Mouse: Novel in Vivo Metabolites Identified by High Performance Liquid Chromatography Coupled to Linear Ion Trap Mass Spectrometry. Xenobiotica 2012, 42 (2), 179-194. https://doi.org/10.3109/00498254.2011.607865.

(8) Shen, S.; Marchick, M. R.; Davis, M. R.; Doss, G. A.; Pohl, L. R. Metabolic Activation of Diclofenac by Human Cytochrome P450 3A4: Role of 5-Hydroxydiclofenac. Chem. Res. Toxicol. 1999, 12 (2), 214-222. https://doi.org/10.1021/tx9802365.

(9) Thorne, C. Diclofenac Pathway, Pharmacokinetics https://www.pharmgkb.org/pathway/PA166163705 (accessed Oct 10, 2019).

(10) Whirl-Carrillo, M.; McDonagh, E. M.; Hebert, J. M.; Gong, L.; Sangkuhl, K.; Thorn, C. F.; Altman, R. B.; Klein, T. E. Pharmacogenomics Knowledge for Personalized Medicine. Clin. Pharmacol. Ther. 2012, 92 (4), 414-417. https://doi.org/10.1038/clpt.2012.96. 
(11) Bort, R.; Macé, K.; Boobis, A.; Gómez-Lechón, M.-J.; Pfeifer, A.; Castell, J. Hepatic Metabolism of Diclofenac: Role of Human CYP in the Minor Oxidative Pathways. Biochem. Pharmacol. 1999, 58 (5), 787-796. https://doi.org/10.1016/S0006-2952(99)00167-7.

(12) Niyonsaba, E.; Easton, M. W.; Feng, E.; Yu, Z.; Zhang, Z.; Sheng, H.; Kong, J.; Easterling, L. F.; Milton, J.; Chobanian, H. R.; Deprez, N. R.; Cancilla, M. T.; Kilaz, G.; Kenttämaa, H. I. Differentiation of Deprotonated Acyl-, N -, and O -Glucuronide Drug Metabolites by Using Tandem Mass Spectrometry Based on Gas-Phase Ion-Molecule Reactions Followed by Collision-Activated Dissociation. Anal. Chem. 2019, 91 (17), 11388-11396. https://doi.org/10.1021/acs.analchem.9b02717.

(13) Anders, M. W. Metabolism of Drugs by the Kidney. Kidney Int. 1980, 18 (5), 636-647. https://doi.org/10.1038/ki.1980.181.

(14) Boelsterli, U. Diclofenac-Induced Liver Injury: A Paradigm of Idiosyncratic Drug Toxicity. Toxicol. Appl. Pharmacol. 2003, 192 (3), 307-322. https://doi.org/10.1016/S0041008X(03)00368-5.

(15) Regan, S. L.; Maggs, J. L.; Hammond, T. G.; Lambert, C.; Williams, D. P.; Park, B. K. Acyl Glucuronides: The Good, the Bad and the Ugly. Biopharmaceutics and Drug Disposition. 2010. https://doi.org/10.1002/bdd.720.

(16) Vaz, A. D. N.; Wang, W. W.; Bessire, A. J.; Sharma, R.; Hagen, A. E. A Rapid and Specific Derivatization Procedure to Identify Acyl-Glucuronides by Mass Spectrometry. Rapid Commun. Mass Spectrom. 2010, 24 (14), 2109-2121. https://doi.org/10.1002/rcm.4621.

(17) Alam, M. A.; Al-Jenoobi, F. I.; Al-Mohizea, A. M. High-Throughput Ultra-Performance LCMS-MS Method for Analysis of Diclofenac Sodium in Rabbit Plasma. J. Chromatogr. Sci. 2015, 53 (1), 47-53. https://doi.org/10.1093/chromsci/bmu011.

(18) Zhang, Y.; Han, Y.-H.; Putluru, S. P.; Matta, M. K.; Kole, P.; Mandlekar, S.; Furlong, M. T.; Liu, T.; Iyer, R. A.; Marathe, P.; Yang, Z.; Lai, Y.; Rodrigues, A. D. Diclofenac and Its Acyl Glucuronide: Determination of In Vivo Exposure in Human Subjects and Characterization as Human Drug Transporter Substrates In Vitro. Drug Metab. Dispos. 2016, 44 (3), 320328. https://doi.org/10.1124/dmd.115.066944.

(19) Dorado, P.; Berecz, R.; Cáceres, M. C.; LLerena, A. Analysis of Diclofenac and Its Metabolites by High-Performance Liquid Chromatography: Relevance of CYP2C9 Genotypes in Diclofenac Urinary Metabolic Ratios. J. Chromatogr. B 2003, 789 (2), 437442. https://doi.org/10.1016/S1570-0232(03)00137-5.

(20) Keski-Hynnilä, H.; Luukkanen, L.; Taskinen, J.; Kostiainen, R. Mass Spectrometric and Tandem Mass Spectrometric Behavior of Nitrocatechol Glucuronides: A Comparison of Atmospheric Pressure Chemical Ionization and Electrospray lonization. J. Am. Soc. Mass Spectrom. 1999, 10 (6), 537-545. https://doi.org/10.1016/S1044-0305(99)00021-5.

(21) Drexler, D. M.; Tannehill-Gregg, S. H.; Wang, L.; Brock, B. J. Utility of Quantitative WholeBody Autoradiography (QWBA) and Imaging Mass Spectrometry (IMS) by Matrix-Assisted Laser Desorption/Ionization (MALDI) in the Assessment of Ocular Distribution of Drugs. J. Pharmacol. Toxicol. Methods 2011, 63 (2), 205-208. https://doi.org/10.1016/j.vascn.2010.10.003.

(22) Solon, E. G. Autoradiography Techniques and Quantification of Drug Distribution. Cell Tissue Res. 2015, 360 (1), 87-107. https://doi.org/10.1007/s00441-014-2093-4. 
(23) Solon, E. G.; Schweitzer, A.; Stoeckli, M.; Prideaux, B. Autoradiography, MALDI-MS, and SIMS-MS Imaging in Pharmaceutical Discovery and Development. AAPS J. 2010, 12 (1), 11-26. https://doi.org/10.1208/s12248-009-9158-4.

(24) Solon, E. G.; Kraus, L. Quantitative Whole-Body Autoradiography in the Pharmaceutical Industry. J. Pharmacol. Toxicol. Methods 2001, 46 (2), 73-81. https://doi.org/10.1016/S1056-8719(02)00161-2.

(25) Kertesz, V.; Van Berkel, G. J.; Vavrek, M.; Koeplinger, K. A.; Schneider, B. B.; Covey, T. R. Comparison of Drug Distribution Images from Whole-Body Thin Tissue Sections Obtained Using Desorption Electrospray Ionization Tandem Mass Spectrometry and Autoradiography. Anal. Chem. 2008, 80 (13), 5168-5177. https://doi.org/10.1021/ac800546a.

(26) Norris, J. L.; Caprioli, R. M. Analysis of Tissue Specimens by Matrix-Assisted Laser Desorption/Ionization Imaging Mass Spectrometry in Biological and Clinical Research. Chem. Rev. 2013, 113 (4), 2309-2342. https://doi.org/10.1021/cr3004295.

(27) Greer, T.; Sturm, R.; Li, L. Mass Spectrometry Imaging for Drugs and Metabolites. J. Proteomics 2011, 74 (12), 2617-2631. https://doi.org/10.1016/j.jprot.2011.03.032.

(28) Prideaux, B.; Lenaerts, A.; Dartois, V. Imaging and Spatially Resolved Quantification of Drug Distribution in Tissues by Mass Spectrometry. Curr. Opin. Chem. Biol. 2018, 44, 93100. https://doi.org/10.1016/j.cbpa.2018.05.007.

(29) Schulz, S.; Becker, M.; Groseclose, M. R.; Schadt, S.; Hopf, C. Advanced MALDI Mass Spectrometry Imaging in Pharmaceutical Research and Drug Development. Curr. Opin. Biotechnol. 2019, 55, 51-59. https://doi.org/10.1016/j.copbio.2018.08.003.

(30) Karlsson, O.; Hanrieder, J. Imaging Mass Spectrometry in Drug Development and Toxicology. Arch. Toxicol. 2017, 91 (6), 2283-2294. https://doi.org/10.1007/s00204-0161905-6.

(31) Buchberger, A. R.; DeLaney, K.; Johnson, J.; Li, L. Mass Spectrometry Imaging: A Review of Emerging Advancements and Future Insights. Anal. Chem. 2018, 90 (1), 240-265. https://doi.org/10.1021/acs.analchem.7b04733.

(32) Cornett, D. S.; Reyzer, M. L.; Chaurand, P.; Caprioli, R. M. MALDI Imaging Mass Spectrometry: Molecular Snapshots of Biochemical Systems. Nat. Methods 2007, 4 (10), 828-833. https://doi.org/10.1038/nmeth1094.

(33) Sugiura, Y.; Setou, M. Imaging Mass Spectrometry for Visualization of Drug and Endogenous Metabolite Distribution: Toward In Situ Pharmacometabolomes. J. Neuroimmune Pharmacol. 2010, 5 (1), 31-43. https://doi.org/10.1007/s11481-009-91626.

(34) Cornett, D. S.; Frappier, S. L.; Caprioli, R. M. MALDI-FTICR Imaging Mass Spectrometry of Drugs and Metabolites in Tissue. Anal. Chem. 2008, 80 (14), 5648-5653. https://doi.org/10.1021/ac800617s.

(35) Takyi-Williams, J.; Liu, C.-F.; Tang, K. Ambient lonization MS for Bioanalysis: Recent Developments and Challenges. Bioanalysis 2015, 7 (15), 1901-1923. https://doi.org/10.4155/bio.15.116.

(36) Castellino, S.; Groseclose, M. R.; Wagner, D. MALDI Imaging Mass Spectrometry: Bridging Biology and Chemistry in Drug Development. Bioanalysis 2011, 3 (21), 2427-2441. https://doi.org/10.4155/bio.11.232. 
(37) Swales, J. G.; Hamm, G.; Clench, M. R.; Goodwin, R. J. A. Mass Spectrometry Imaging and Its Application in Pharmaceutical Research and Development: A Concise Review. Int. J. Mass Spectrom. 2019, 437, 99-112. https://doi.org/10.1016/j.ijms.2018.02.007.

(38) Korfmacher, W.; Yagnik, G.; Luo, Y.; Ho, S.; Shen, L.; Wilper, T.; Norton, K.; Solon, E.; Liu, H.; Savage, S.; O'Shea, T. Comparison of LESA-MS to MALDI-MS for Mouse Whole Body Tissue Profiling: Diclofenac and Major Metabolites. In 64th ASMS Conference on Mass Spectrometry and Allied Topics; San Antonio, 2016.

(39) Kertesz, V.; Van Berkel, G. J. Automated Liquid Microjunction Surface Sampling-HPLCMS/MS Analysis of Drugs and Metabolites in Whole-Body Thin Tissue Sections.

Bioanalysis 2013, 5 (7), 819-826. https://doi.org/10.4155/bio.13.42.

(40) Chen, B.; Vavrek, M.; Cancilla, M. T. Optimization of DropletProbe-Mass Spectrometry for Whole-Body Tissue Distribution Analysis of Drug-Like Molecules. J. Am. Soc. Mass Spectrom. 2020. https://doi.org/10.1021/jasms.0c00168.

(41) Hintikka, L.; Kuuranne, T.; Leinonen, A.; Thevis, M.; Schänzer, W.; Halket, J.; Cowan, D.; Grosse, J.; Hemmersbach, P.; Nielen, M. W. F.; Kostiainen, R. Liquid ChromatographicMass Spectrometric Analysis of Glucuronide-conjugated Anabolic Steroid Metabolites: Method Validation and Interlaboratory Comparison. J. Mass Spectrom. 2008, 43 (7), 965973. https://doi.org/10.1002/jms.1434.

(42) Roach, P. J.; Laskin, J.; Laskin, A. Nanospray Desorption Electrospray lonization: An Ambient Method for Liquid-Extraction Surface Sampling in Mass Spectrometry. The Analyst 2010, 135 (9), 2233. https://doi.org/10.1039/c0an00312c.

(43) Laskin, J.; Heath, B. S.; Roach, P. J.; Cazares, L.; Semmes, O. J. Tissue Imaging Using Nanospray Desorption Electrospray Ionization Mass Spectrometry. Anal. Chem. 2012, 84 (1), 141-148. https://doi.org/10.1021/ac2021322.

(44) Lanekoff, I.; Heath, B. S.; Liyu, A.; Thomas, M.; Carson, J. P.; Laskin, J. Automated Platform for High-Resolution Tissue Imaging Using Nanospray Desorption Electrospray Ionization Mass Spectrometry. Anal. Chem. 2012, 84 (19), 8351-8356. https://doi.org/10.1021/ac301909a.

(45) Lanekoff, I.; Laskin, J. Imaging of Lipids and Metabolites Using Nanospray Desorption Electrospray Ionization Mass Spectrometry. In Mass spectrometry imaging of small molecules: Methods in molecular biology; Humana Press, 2015; pp 99-106. https://doi.org/10.1007/978-1-4939-1357-2_10.

(46) Lanekoff, I.; Thomas, M.; Carson, J. P.; Smith, J. N.; Timchalk, C.; Laskin, J. Imaging Nicotine in Rat Brain Tissue by Use of Nanospray Desorption Electrospray lonization Mass Spectrometry. Anal. Chem. 2013, 85 (2), 882-889. https://doi.org/10.1021/ac302308p.

(47) Lanekoff, I.; Thomas, M.; Laskin, J. Shotgun Approach for Quantitative Imaging of Phospholipids Using Nanospray Desorption Electrospray lonization Mass Spectrometry. Anal. Chem. 2014, 86 (3), 1872-1880. https://doi.org/10.1021/ac403931r.

(48) Nguyen, S. N.; Sontag, R. L.; Carson, J. P.; Corley, R. A.; Ansong, C.; Laskin, J. Towards High-Resolution Tissue Imaging Using Nanospray Desorption Electrospray lonization Mass Spectrometry Coupled to Shear Force Microscopy. J. Am. Soc. Mass Spectrom. 2018, 29 (2), 316-322. https://doi.org/10.1007/s13361-017-1750-8.

(49) Yin, R.; Kyle, J.; Burnum-Johnson, K.; Bloodsworth, K. J.; Sussel, L.; Ansong, C.; Laskin, J. High Spatial Resolution Imaging of Mouse Pancreatic Islets Using Nanospray Desorption 
Electrospray Ionization Mass Spectrometry. Anal. Chem. 2018, 90 (11), 6548-6555. https://doi.org/10.1021/acs.analchem.8b00161.

(50) Yin, R.; Burnum-Johnson, K. E.; Sun, X.; Dey, S. K.; Laskin, J. High Spatial Resolution Imaging of Biological Tissues Using Nanospray Desorption Electrospray Ionization Mass Spectrometry. Nat. Protoc. 2019, 14 (12), 3445-3470. https://doi.org/10.1038/s41596019-0237-4.

(51) Bergman, H.-M.; Lundin, E.; Andersson, M.; Lanekoff, I. Quantitative Mass Spectrometry Imaging of Small-Molecule Neurotransmitters in Rat Brain Tissue Sections Using Nanospray Desorption Electrospray Ionization. The Analyst 2016, 141 (12), 3686-3695. https://doi.org/10.1039/C5AN02620B.

(52) Nguyen, S. N.; Liyu, A. V.; Chu, R. K.; Anderton, C. R.; Laskin, J. Constant-Distance Mode Nanospray Desorption Electrospray Ionization Mass Spectrometry Imaging of Biological Samples with Complex Topography. Anal. Chem. 2017, 89 (2), 1131-1137. https://doi.org/10.1021/acs.analchem.6b03293.

(53) Mesa Sanchez, D.; Creger, S.; Singla, V.; Kurulugama, R. T.; Fjeldsted, J.; Laskin, J. Ion Mobility-Mass Spectrometry Imaging Workflow. J. Am. Soc. Mass Spectrom. 2020. https://doi.org/10.1021/jasms.0c00142.

(54) Le, J. Drug Metabolism https://www.merckmanuals.com/professional/clinicalpharmacology/pharmacokinetics/drug-metabolism.

(55) Schonborn, J. L.; Gwinnutt, C. The Role of the Liver in Drug Metabolism; 2010.

(56) Almazroo, O. A.; Miah, M. K.; Venkataramanan, R. Drug Metabolism in the Liver. Clin. Liver Dis. 2017, 21 (1), 1-20. https://doi.org/10.1016/j.cld.2016.08.001.

(57) Remmer, H. The Role of the Liver in Drug Metabolism. Am. J. Med. 1970, 49 (5), 617-629. https://doi.org/10.1016/S0002-9343(70)80129-2.

(58) Patel, S. R. Bioanalytical Challenges and Strategies for Accurately Measuring Acyl Glucuronide Metabolites in Biological Fluids. Biomed. Chromatogr. 2020, 34 (1), e4640. https://doi.org/10.1002/bmc.4640. 